\title{
A Study of the Effectiveness of Blackboard Collaborate for Conducting Synchronous Courses at Multiple Locations
}

\author{
Guillermo Tonsmann, PhD \\ Associate Professor of Computer Science \\ Park University
}

\begin{abstract}
This paper discusses the effectiveness of the videoconferencing software Blackboard Collaborate for carrying out instruction at college level to students attending classes synchronously at multiple locations. The paper describes the motivation for this study, a brief literature review on the subject, the methodology used, and the results obtained. The main conclusion of this study is the confirmation that synchronous instruction, in general, and Blackboard Collaborate, in particular, is an effective environment for tuition of students at a distance. Based on this study, several recommendations to be used in synchronous education are provided.
\end{abstract}

\section{Motivation}

This paper will analyze the experience the author had in teaching Discrete Mathematics using Blackboard Collaborate, videoconferencing software that allowed students at various locations in the United States to take part in live regular class sessions. The course was designed to test the feasibility of carrying out a course using only remote synchronous connections between instructor and students, and to gain firsthand experience in the process.

Park University, the author's institution, currently delivers asynchronous distance education to more than 20,000 students worldwide. The University currently uses eCollege and eCompanion as its main software platform for course delivery. Park University has also more than 40 campus centers at various locations in the United States where face-to-face instruction is offered in various disciplines. Blackboard Collaborate software was recently acquired to be used as an administrative tool. Given this context, the main motivations for the development of this course were:

- The desire to increase student enrollment by fighting fragmentation of student population. This condition appears when sections of the same course are cancelled due to low enrollment at various campus centers. Linking students from various campus centers in a synchronous course would avoid eliminating these sections and satisfy course loads.

- The desire to provide added sections of courses that may not be offered regularly at campus centers due to unavailability of credentialed faculty for the specific disciplines.

- The low appeal for online offerings amongst a significant number of campus center students.

- $\quad$ The desire to increase the quantity of course offerings at campus centers and limit the number of cancellations to improve customer service.

\section{Literature Review}

Scholarly articles and papers dealing with the use of synchronous technologies for teaching on the Internet have been produced since these tools have been made more widely available for the general public in the first decade of $21^{\text {st }}$ century. Foreman and Jenkins (2005) described a set of desirable characteristics a Web Conferencing System (or "Webcon", as they call it) should have to enhance the synchronous learning experience. A survey of then-available tools for synchronous and asynchronous online learning was also presented the same year by Repman, Zinskie, and Carlson (2005), and an evaluation of a combined synchronous and 
asynchronous experience by Teng and Taveras (2004), describes the initial challenges found in integrating synchronous technology in online education.

In the ensuing years, various papers compared the performance of synchronous education against other delivery modes. Moridani (2007) presents the results of a study that compares synchronous with asynchronous teaching. Similar comparisons are presented by Roblyer, Freeman, Donaldson, and Maddox (2007), Skylar (2009), and Al-Nuaim (2012), in different software environments and curricula. The conclusions of all these studies show that both delivery modes are comparable in their effectiveness to instruct. In particular, in Moridani (2007), students showed their preference for the greater interaction that synchronous education provides. This correlates well with the results of a later study on perceptions of students who take synchronous courses, presented by Karal, Cebi, and Ayca (October, 2011). In this study, even though students were initially dubious of the benefits of this modality of learning, once they were engaged in course activities, their attitude was far more favorable.

Synchronous online learning was also compared with face-to-face education by Koeber and Wright (2008), and while students preferred the greater personal contact with instructor and other students in the face-to-face environment, they recognized the potential of synchronous online learning in situations where the traditional class environment is not available. As a counterpoint, in her dissertation, Phillips (2010) reports that a similar comparative study between face-to-face, synchronous, and blended/hybrid environments gives higher marks to the synchronous modality in academic success, retention, grades, and overall. She attributes these results to pedagogical and media attributes of the synchronous environment.

The literature on the subject also includes reports on the use of diverse technology in the synchronous realm. Gibbs and Larson (2007) relate an experience using MediaSiteLive, a videoconferencing system for lectures. In similar fashion, Cunningham, Fagersten, and Holmsten (2010) present the results of using Marratech and AdobeConnect, while Stewart, Harlow, and DeBacco (2011) report their experiences with Google Video chat. In turn, Wang and Chen (2012) used a "Synchronous Learning Management System" (SLMS) called 3C. This present paper is also following this thematic line by reporting on the use of Blackboard Collaborate for synchronous education.

Finally, two papers also describe the use of synchronous technology to support various educational efforts. Burke, Chaney, and Kirsten (2010) used videoconference technology for multicultural studies in health education, while Karal, Cebi, and Ayca (April, 2011) reported on the use of synchronous technology to support education with handicapped people from the student perspective.

\section{Methodology}

The course that was selected for synchronous delivery was Discrete Mathematics. The main reason for choosing this course was the scarcity of face-toface offerings of this course among campus centers due to low enrollment or lack of qualified instructors. Because of this situation, students regularly elect to take the course online; however, many of them find it extremely difficult to learn the course material without attending face-to-face class sessions. A synchronous offering of this course could provide the more personal attention typical of face-to-face classes, along with the convenience of online courses' ubiquity.

The author directed class sessions from his office at the Park University Campus Center in Austin, Texas, while students attended these sessions from various locations in Austin, Texas; Minot, North Dakota; and Charleston, South Carolina. Every participant had full duplex audio and video communications. The course was offered in an 8-week term between October and December 2012. There were two class sessions per week, each lasting $2 \frac{1}{2}$ hours.

In an effort to promote and effectively prepare for this course, six informative pre-sessions were offered to students interested in learning about the 
synchronous course. During the sessions, prospective students tested their individual connections, learned the basis of being participants of a Blackboard Collaborate session, and viewed a limited sample of the course contents. Some campus center administrators who also attended these sessions got acquainted with the mechanics of the course and the requirements it would set for their campus centers and their students. Students who wanted to register for this class were required to attend one of these pre-sessions. A total of nine students registered by the end of add/drop period.

Besides Blackboard Collaborate used in class sessions, the course made use of eCompanion as a repository of course documentation, delivery of assignments, administration of quizzes, and gradebook keeping.

All class sessions were recorded by the Blackboard Collaborate system, and all students had access to them immediately after the class ended. This way, students who missed a class, or those who attended but desired to review some topics, could have access to the class sessions again. Course material was explicitly prepared for this form of delivery based on enhanced PowerPoint presentations. This material was made available to students at various stages of the course.

Final exams were proctored on-site by the respective campus center administrations. An anonymous survey was presented to students at the end of the course. The analysis of their responses is included in this paper.

\section{The Software Platform}

Blackboard Collaborate facilitated most of the activities associated with traditional instruction:

- A presentation window allowed delivery of content. This window was accessible to all course participants and was used extensively on discussions over course material. Premade PowerPoint presentations were incorporated in this window, and participants could make annotations to their live display, facilitating the communication.

- Students could also interact with the instructor and each other on presentations using their voice and also a chat system. The chat system was used by students to exchange messages among themselves without disturbing the class in progress and to answer instructor's questions during class.

- Students were polled at various stages of the presentation to gauge the level of understanding and engagement with the class. The software platform facilitated this activity by having an automated polling mechanism that allowed the instructor to present objective questions to students and gather the answers. Polling questions included "Is this concept understood?" and " Should we continue to another topic?", but there were also more sophisticated ones, such as presenting multiple choice questions based on the topic under study and allowing students to answer with the choices provided by the system.

- Blackboard Collaborate allowed for the recording of its sessions. All sessions were recorded and made available to all students after the end of each class and throughout the length of the course. This feature was used by students who missed classes and the ones who wanted refreshers on the topics covered.

- The software platform also allowed for group work, which involved separating students into teams through the use of the breakout room feature. Students used this feature to work in teams on additional exercises, designed to reinforce concepts explained in that class session. Break-out rooms were created randomly, so students could interact with different individuals every class meeting. Students usually interacted with members of their groups using their voice and another presentation window specific to that group. The 
instructor rotated amongst the various breakout rooms, verifying progress and giving advice when necessary.

- Syllabus, assignments, and other course material were delivered synchronously to students during class sessions, but copies of these documents were also stored in eCompanion for students' reference.

- Office hours were carried out using the same software platform two hours before the beginning of the class and also after class when students requested them.

All these activities were performed seamlessly, and instructor and students became more adept at using all these platform features rather rapidly in the course.

\section{Analysis}

\section{Software Platform I ssues}

The only specific problem with the software platform was in the writing of mathematical equations. Blackboard Collaborate offered various alternatives to address this issue; however, none of them were completely satisfactory. I nitially, the instructor provided special libraries of symbols to be used when discussing mathematical expressions, but these symbols were difficult to manipulate when arranged in groups to form more complex expressions. For example, the following expression was difficult to write during a live session:

$$
\sum_{i=1}^{n+1} i=\frac{(n+1) \cdot((n+1)+1)}{2}
$$

An alternative to using these symbols was to use text boxes, available in the presentation window. Unfortunately, they organize the content in paragraphs, without support for equations, and they had a single baseline for text, making it impossible to have text above or below symbols as shown above.

A more effective solution was to use the drawing capabilities of the presentation window to draw rather than type mathematical expressions. This worked better to organize the elements of the

Synchronous teaching...deals with the same pedagogical issues present in other learning environments.

expressions in the right position, but given that each expression is made up of many symbols, it was difficult to manipulate them as a group. It was time-consuming and took more steps than was practical. The process was improved by the use of touch screens, but this facility was available only to the instructor. Students had to keep battling with the expressions on their own installations. Unfortunately, touch screens were not as sensitive as mouse devices, because the mouse has more control of fine movements within a small area.

In the end, higher dexterity obtained by continuous practice, and a lot of patience from all class participants, made the use of the mouse to draw mathematical expressions the option to carry on with lessons. It also helped a lot that the later topics in the course did not rely on the manipulation of complicated formulas.

\section{Pedagogical I ssues}

Synchronous teaching also deals with the same pedagogical issues present in other learning environments. The instructor employed various policies and strategies common to other teaching modalities: 
- Attendance was required of students for all classes. It is well-known that regular student attendance increases course scores and overall learning. Even though students could review recordings of class sessions, attendance was still required. Most students attended regularly, others did not. As was expected, the most egregious absentees failed the course. There were no penalties directly associated with absences. However, Discrete Mathematics is difficult enough in any form of delivery, so that if a student does not participate actively, her or his grades are likely to be lowered. The fact that recordings of each class session were available to students did not replace the benefits of actual attendance. One reason is that the class required participation in handson and group activities, and the recordings could not reproduce these same experiences. Also, recordings were the same length time as the class meetings ( $21 / 2$ hours), and students who might have trouble securing time to attend class sessions may also have trouble finding enough time to view and understand the recordings.

- Regarding attendance, this teaching modality also achieved what might have been difficult to do in other modalities. During the first week of class, one student suffered serious medical problems that required hospitalization for several weeks. Even though he could not move from his hospital room, he managed to attend a good number of our class sessions. This kept him focused and up-to-date with the course material. Fortunately, his health improved, and he could attend the proctored exam, and passed the course. This was an important and unexpected benefit of this teaching modality, one that could be aptly employed for teaching mobility-challenged individuals such as handicapped persons and wounded veterans. This observation is consistent with the results of the study by Karal et al. (April, 2011).

- Previous papers in the literature report communication problems due to faulty connections as the main problem in the synchronous environment (Cunningham et al., 2010; Karal et al., October, 2011). To minimize these problems, at the beginning of the course all participants were requested to have headphones with incorporated speakers and microphone to minimize echo during class sessions. This worked relatively well, after an initial period of student adjustment. A web camera was also required of all participants to maintain visual contact. Even though this equipment was used during the first sessions, most students preferred not to activate them. At no point during the course were cameras turned on by all participants, and their use was negligible after the initial sessions. Given this fact, the instructor also stopped broadcasting from his web camera from midterm onwards. There are various possible reasons for the lack of web camera usage: difficult set-up, forgetfulness, selfconsciousness on the part of participants, and irrelevance of the video stream, among others. However, the communication and instruction was not hampered in any way by the lack of video feed. In light of this fact, future offerings in this teaching modality may consider dispensing with the web camera requirement altogether. However, this may depend on subject material and the instructor's teaching technique. This observation contradicts the recommendation made by Karal et al. (October, 2011) that suggests the use of more cameras and angles to avoid student boredom. If the course participants can maintain verbal contact, their own video feeds may not be necessary, as long as students are engaged with the other interactive tools of the environment as described in the next paragraph.

- $\quad$ Students were also engaged by their interaction with the presentation window. At various times during presentations, students were queried about the topic at hand and requested to write in the presentation window solutions to problems. Often they also complemented these solutions with oral comments and chat 
entries. These were very effective mechanisms to keep students engaged in the subject matter, regardless of the problems with the software platform that were previously described.

- The breakout rooms proved to be an invaluable technique for student understanding and assimilation of concepts. After the presentation of a main topic with exercises for the whole class, similar exercises were provided to teams in separate breakout rooms. Teams were composed of two to three students. Solving similar problems reinforced the concepts already discussed, and more advanced students could explain to the others in their team the same ideas but in their own words. The instructor moved from room to room, verifying progress and making suggestions when appropriate. This way he could oversee problems with understanding and solve them immediately.

- Like most courses these days, a PowerPoint presentation was prepared for every class. However, for Blackboard Collaborate, the PowerPoint presentations had to be converted to a compatible format for display. This format does not allow premade animations, but converts every PowerPoint slide into a single image. Instructors have to be aware of this fact and plan their presentations accordingly. Under these circumstances, a sequential chain of thoughts or ideas for a topic could be condensed into a single slide, or created sequentially through many slides. The instructor experimented with both of these styles in the class, and obtained better results with the second format. I deas condensed into one slide left little room for annotations during class and became too "busy" for students to grasp at a glance. On the other hand, faster rates of understanding were experienced when students were presented with a step-by-step development of a topic in various slides that could be backtracked when necessary.

- $\quad$ Although these presentations were viewable on class recordings, students also wanted to have independent access to them after hours. The instructor experimented with providing access to the PowerPoint presentations before and after the class. Initially it was thought that giving students access to presentation material before class would spoil class attention and engagement, but it was a happy surprise to see that in fact, the opposite was true. When students had access to the presentation before class, they were already somewhat familiar with the material, but may have some doubts about the complete procedure. The class explanation helped to reinforce their understanding of concepts, rather than their discovery.

- Finally, assessment of the course was made through weekly homework and quizzes, the midterm and final exam. To practice for assessment, every week students were given additional exercises, similar to the ones explained in class. Homework and quizzes were based on previous week's lectures to give students time for preparation, and once again included similar problems to the ones discussed in class. Midterm and final exam also included this kind of problems, emphasizing that the skills being shown in class were the ones being tested on, and the ones necessary for future courses.

\section{Student Feedback}

The course began with nine students. Of those nine, one withdrew in the third week of class. An anonymous student survey was carried out on the last week of the term. Responses from six students were obtained (75\% of total possible). The survey was designed to gather student opinion on various aspects of the course that may have impact on future offerings. Survey questions were divided into three areas:

- Enrollment and preparations. The survey showed that the students preferred face-to-face classes above all, with synchronous courses being a close second, and online being disliked the most. This came from students with experience in all modalities. The course was required of all students, and they 
chose this teaching modality because they did not have it offered face-to-face at their campus centers, did not want to take it online, and/or they thought that it would be an interesting alternative to try. All of them had experienced previous class cancellations while at Park University, and if this course would have been cancelled due to low enrollment, they would have waited for it to be offered face-to-face or until they could no longer wait and had to take it online. The characteristics described here fitted the expected profile for students who may take synchronous courses.

- Blackboard Collaborate. All respondents agreed that the pre-sessions were good enough to understand how Blackboard Collaborate works. They connected to sessions from home, work, and campus centers. There was also one student connecting from the hospital. Most of them had no major difficulties with the environment, but for those who did the problems were mainly due to poor audio reception. They also reported that these problems were solved when they reset their computers and/or software, followed the setup instructions, and/or changed browsers. There were reports of other problems which did not have to do with Blackboard Collaborate, but rather with eCompanion or the campus center. These later problems will be discussed in another section.

- $\quad$ Students were also asked questions regarding the distractions they had in class sessions, and they listed in equal parts either no distractions, echo in the lines, or their own personal distractions. They also were distracted by the annoyance of having to deal with the difficulty of writing formulas in the presentation window by themselves or with other session participants. This problem surely influenced the ranking of its interactive tools as of average use and somewhat above average effectiveness.

- All in all, students indicated that Blackboard Collaborate has very useful features that include its audio capabilities, recordings, polling, and breakout rooms as the most useful. These were also the features that were considered the most effective by students. Chatting and video capabilities were the least useful and effective features.

- Course Features. Respondents agreed completely with the following sentences:

o "I like I can ask questions in class and receive immediate response, instead of using e-mail."

o "I like the opportunity of interacting with other students during class to solve course problems."

o "I like that I can review the class using the recordings."

With regards to the sentence "I like the ability to take classes from wherever I have an Internet connection", all but one student agreed completely. On the other hand, they all somewhat disagreed or disagreed completely with the following statement: "I think the technical difficulties are too big to take a course synchronously."

There was no consensus regarding the difficulty of the course. Four respondents out of the six disagreed with the sentence: "I think taking courses synchronously is more difficult than online or face-to-face." One of the other two students neither agreed nor disagreed with the sentence, while the last one somewhat agreed.

Students indicated that the following issues were done particularly well:

o "I believe this course was very successful. I have enjoyed it a lot. Particularly I liked having options of accessing the class from anywhere with a proper internet connection. At first teaching techniques utilized for this course needed some adjustment but instructor was able to adjust his teaching style which dramatically improved the course and its presentation." 
o "The professor was very patient with the whiteboard (takes forever to write or draw) and with the people who had bad/slow connections. I think the break out rooms were very useful too."

o "The required material was covered in depth and normally done step by step by the instructor. This helped me learn what I thought was difficult material! I would definitely take another synchronous course"

- "Overall was great class and was able to learn material during the sessions and watching the recordings, PowerPoint slides availability was also helpful."

o "Power Point presentations for Graphs and Trees were very well done (or my comprehension of the content went well). The connectedness factor among instructor and students was excellent. Encouraging full class participation and instructor office hour availability-the whole interactiveness thing totally worked."

o "I think the course presentations and the recordings were very professional."

The issue that most students indicated could be improved was the software capabilities with regard to the interaction with the presentation. One student also wanted recordings of the breakout rooms, because they are not part of normal recording. Another student also mentioned that the "flow" of the course could have been improved, but s/he mentioned that the flow was "wonderful" by the fifth week. These changes were predictable, given that this was a pilot course where various issues were tested.

Overall, students' comments in this course were in line with comments made by Discrete Mathematics' students from previous face-to-face classes. All respondents indicated they would recommend this course to other students and that they will also take other courses synchronously.

Given the success of this experience, a second delivery of this course was offered in a later 8-week term, between January and March 2013, using a sister software product called Class Live Pro. This product had features identical to Blackboard Collaborate with similar interface. Based on the student feedback on the first experience, some modifications were made to the course: Fewer preparation sessions were needed to introduce students to the classroom environment; some chatting features were disabled to improve some possible source of student distraction; the instructor implemented early use of a pen tablet to draw formulas; and video cameras were not required of students to connect to the sessions. Seven students were enrolled in the class. The delivery of this course went more smoothly and its outcomes closely agreed with the results obtained in the first experience in regards to platform, pedagogical, and student related issues. This fact emphasizes the repeatability of these results and reinforces the author's position that the use of synchronous technologies is an effective alternative for education at a distance.

\section{Administrative I ssues}

Students for this course were recruited from various Park campus centers. The directors of those centers were given absolute autonomy in regards to how students were expected to attend class sessions. Students at one campus center were allowed to connect to class sessions from wherever they deemed it convenient with their own computers. Other campuses requested students to attend the campus center and use campus equipment, arguing better attendance control. Even though these students made the effort to comply with this request, they would have preferred not to. Some of them could get better connectivity and access to better equipment on their own. Given that attendance control was never an issue, because it was recorded by the instructor and not by the campus centers, it would be advisable to let all students decide which venue will be best for them to connect to class sessions. Proctoring of the final exam was carried out by campus centers. 


\section{Conclusions and Recommendations}

1. Blackboard Collaborate provides a good alternative to traditional face-to-face and online offerings. It requires from students the same time commitment as faceto-face classes, but gives flexibility to remote students to connect from wherever they may be. This flexibility was demonstrated when a student had to be hospitalized in the first week of class. He followed most of class sessions from his patient bed in the hospital.

2. Blackboard Collaborate is a reasonable software platform to carry on synchronous sessions. The environment is stable, and can easily handle sessions of 3 hours or more. Students need to be trained in their use before the term begins to avoid delays in dealing with course material.

3. The main deficiency of the software platform was its clumsiness in manipulating mathematical equations. This was a major source of frustration for all participants. The most reasonable solution to this problem is to treat mathematical equations as drawings on a canvas. This solution may require a high level of dexterity with the mouse from participants. All in all, communication was possible, albeit slightly delayed by the technology. In courses where the use of mathematical equations is not as heavy as in a math course, this environment will accommodate the delivery of material seamlessly. If writing equations is essential for a course, the use of a point-and-draw device, like a pen tablet, will be advisable, at least on the instructor side.

4. It is advisable to provide off-line course material to students in advance of class sessions. This helps students to prepare before a class, and they can later refer to this material as part of their class notes. Besides this material, sessions should also be recorded. While missing students could readily benefit from these recordings, it was shown that in fact, students who attended the class also used the recordings to re-examine concepts that were not clear or to prepare for exams.

5. Even though students could see the recordings of a class afterwards, attendance was mandatory because every session required team participation to solve course problems. Breakout rooms are a very effective way to reinforce course material. After a new concept is presented and applied in class, students are broken up in teams of two to solve similar problems. They can interact with their team members, and the instructor can supervise development and give individual advice to students who are struggling or have questions on the topic. Student interaction also allows students to learn from each other by comparing their understanding and the way they would apply it to new situations. Students really help each other to learn the material. At the practical level, the process of breaking up students into teams and having them work on a task is much more efficient than in a traditional class or an asynchronous online class. The groups are easily created and managed with a few keystrokes, and students really participate in the task, because the environment and a watchful instructor keep them focused on the goal to be achieved.

6. At the end of the term, it was reassuring to see that student performance followed a typical bell-shaped curve, with few students at both ends of the spectrum and the bulk around the grade of " $\mathrm{B}$ ". It was also interesting to observe that this teaching modality is not immune to challenges encountered in other forms of delivery: absences, tardiness, sickness, and student withdrawals. All these situations were a good test for this course and were as effectively dealt with as in face-to-face and online classes.

\section{References}

Al-Nuaim, H. A. (2012). The use of virtual classrooms in E-Learning: A case study in King Abdulaziz University, Saudi Arabia. E-Learning and Digital Media, 9(2), 211-222.
Burke, S. C., Chaney, B. H., \& Kirsten, W. (2010). International videoconferencing for public health education: Linking the U.S. and Germany. American J ournal of Health Education, 41(1), 53-59. 
Cunningham, U., Fagersten, K. B., \& Holmsten, E. (2010). Can you hear me, Hanoi? Compensatory mechanisms employed in synchronous net-based English language learning. International Review of Research in Open and Distance Learning, 11(1), 161-177.

Foreman, J., \& Jenkins, R. (2005). Full-featured web conferencing systems. Innovate: J ournal of Online Education, 1(4), n4.

Gibbs, B., \& Larson, E. (2007). Using video conferencing in lecture classes. Innovate: Journal of Online Education, 3(5), n5.

Karal, H., Cebi, A., \& Turgut, Y. E. (2011, April). Synchronic distance education from the perspective of a handicapped person. Turkish Online J ournal of Distance Education, 12(2), 183-192.

Karal, H., Cebi, A., \& Turgut, Y. E. (2011, October). Perceptions of students who take synchronous courses through video conferencing about distance education. Turkish Online Journal of Educational Technology - TOJ ET, 10(4), 276-293.

Koeber, C., \& Wright, D. W. (2008). On the outside teaching in: Using Internet video-conferencing to instruct an introductory sociology course from a remote location. Teaching Sociology, 36(4), 331-343.

Moridani, M. (2007). Asynchronous video streaming vs. synchronous videoconferencing for teaching a pharmacogenetic parmacotherapy course. American J ournal of Pharmaceutical Education, 71, 1-10.
Phillips, S. K. (2010). Providing access to developmental reading courses at the community college: An evaluation of three presentation modes (Doctoral Dissertation). Available from ProQuest Dissertations and Thesis database. (UMI No. 3446502)

Repman, J., Zinskie, C., \& Carlson, R. D. (2005). Effective use of CMC tools in interactive online learning. Computers in the Schools, 22(1-2), 57-69.

Roblyer, M. D., Freeman, J., Donaldson, M. B., \& Maddox, M. (2007). A comparison of outcomes of virtual school courses offered in synchronous and asynchronous formats. Internet and Higher Education, 10(4), 261-268.

Skylar, A. A. (2009). A comparison of asynchronous online text-based lectures and synchronous interactive web conferencing lectures. Issues in Teacher Education, 18(2), 69-84.

Stewart, A. R., Harlow, D. B., \& DeBacco, K. (2011). Students' experience of synchronous learning in distributed environments. Distance Education, 32(3), 357-381.

Teng, T., \& Taveras, M. (2004). Combining live video and audio broadcasting, synchronous chat, and asynchronous open forum discussions in distance education. Journal of Educational Technology Systems, 33(2), 121-129.

Wang, Y., \& Chen, N. (2012). The collaborative language learning attributes of cyber face-to-face interaction: The perspectives of the learner. Interactive Learning Environments, 20(4), 311-330.

Guillermo Tonsmann is Associate Professor of Computer Science at Park University since 2007. He obtained his Doctorate degree in Computer Science from Louisiana State University, at Baton Rouge, Louisiana in 2001. He also holds an Honors BS in Computer Science from the University of South Africa (UNISA, 1995), a Masters in Engineering from Potchefstroom, South Africa (1993) and a BS in Chemical Engineering from Universidad Nacional de Ingenieria, Lima, Peru (1984). 